\title{
TYPE 2 DIABETES MELLITUS AND VITAMIN D STATUS - A CASE CONTROL STUDY
}

Prakash Kikkeri Gowdaiah, Aravind. G. N, Rita Christopher.

1. Associate Professor. Department of Medicine, Bangalore Medical College and Research Institute.Bangalore

2. Assistant Professor. Department of Medicine, Bangalore Medical College and Research Institute.Bangalore

3. Professor \& HOD. Department of Neurochemistry, Bangalore Medical College and Research Institute.Bangalore

\section{CORRESPONDING AUTHOR:}

Dr. Prakash Kikkeri Gowdaiah,

Associate Professor, Department of Medicine,

Bangalore Medical College and Research Institute,

Bangalore-560002,

E-mail: kikkeri47@yahoo.com.

ABSTRACT: OBJECTIVE: Both type 2 DM and vitamin D deficiency are widely prevalent in India. Since, vitamin $\mathrm{D}$ is known to affect both insulin secretion and action either directly by gene modulation via vitamin $\mathrm{D}$ receptors or indirectly by altering calcium metabolism and transcellular calcium flux, we wanted to establish whether patients with type 2 DM have lower levels of vitamin D when compared to that of controls. MATERIAL AND METHODS: This was a cross sectional case control observational study, conducted from April 2011 to March 2012. Patients attending the diabetes clinic at Victoria Hospital, Bangalore were recruited as cases. Age and sex matched non diabetic patient's attendants and hospital staff were recruited as controls, after obtaining an informed consent in writing. After physical examination and anthropometric measurements, fasting serum samples were collected for estimation of $25(\mathrm{OH})$ D levels and other biochemical parameters. RESULTS:242 subjects were included in the study, of which 139 were cases and 103 controls. Serum 25(OH) Dlevels $\leq 30 \mathrm{ng} / \mathrm{ml}$ was found in 122 cases and 89 controls which was not statistically significant $(\mathrm{p}=0.658)$. CONCLUSION: In our study $87 \%$ of subjects (i.e. 211 of 242) were having less than optimal levels of vitamin D levels. This high level of prevalence of vitamin D deficiency is in conformation with results of other similar studies reported from India. Though statistically not significant, males andnonvegetarians had slightly higher levels of vitamin D. we could not establish an inverse association between serum vitamin D levels and prevalent type $2 \mathrm{DM}$, probably because of cross sectional study design, small sample size, high prevalence of vitamin D deficiency and other unknown confounding factors.

KEY WORDS: Type 2 Diabetes mellitus, Vitamin D

INTRODUCTION: India leads the world with largest number of diabetic subjects, earning the dubious distinction of being termed as the "Diabetes Capital of the World". According to the data published by International Diabetes Federation in 2006, the number of people with diabetes in India is likely to increase from 40.9 million to 60.9 million by $2025^{[1]}$. Identification of easily modifiable environmental risk factors is urgently needed to curtail the epidemic of Type 2 diabetes mellitus in India.

In spite of abundant sunshine, vitamin D deficiency is widely prevalent in our country in all regions and age groups. About $70 \%$ of adults in both urban and rural areas were found to be vitamin D deficient, in a study by Harinarayanetal[2, 3, 4]. 
Vitamin D is unique because, it is a vitamin synthesized in the skin and functions as a steroid hormone after conversion to its active form 1-25 (OH) D by 1 alpha hydroxylase enzyme in the renal tubule. Research over the past few years has shown that the pleuripotent steroid hormone 1,25(OH) D initiates physiological responses in more than 36 cell types and is synthesized in more than 10 extra renal organs. Vitamin D deficiency has been proposed to impair pancreatic Beta cell function, decrease insulinsecretion and sensitivity and promote systemic inflammation, either directly by gene modulation via vitamin D receptors or indirectly by altering calcium metabolism and transcellular calcium flux ${ }^{[5,6,7,8,9]}$.

Pittas AG et al[9], in their systematic review and meta-analysis have demonstrated inverse relationship (though inconsistent) between circulating levels of $25-\mathrm{OH}$ vitamin $\mathrm{D}$, the main metabolite of vitamin D and type 2 diabetes mellitus.

Since, both type 2 diabetes mellitus and vitamin D deficiency are highly prevalent in India, this study is undertaken to assess the vitamin D status of the study population by measuring serum 25-OH(D) levels, and to test whether patients with type 2 diabetes mellitus have lower levels of vitamin D when compared to that of age and sex matched controls.

MATERIALS AND METHODS: This study was approved by the ethics committee of our institution (Victoria Hospital attached to Bangalore Medical College and Research Institute) and written consent was obtained from all the participants. Patients attending diabetes clinic at Victoria hospital, Bangalore, were recruited as cases. While patient's attendants and staff of Victoria hospital were the source from which controls were recruited. We investigated 242 randomly selected subjects 30 to 70 years of age. This was an observational study conducted from April 2011to March 2012, designed as cross sectional, case control type. There were two groups. The first group included 139 cases, subjects with type 2 diabetes mellitus of varying duration (newly detected to 30 yrs.) and second group included 103 controls, subjects who were age and sex matched.

Demographic and necessary clinical data were collected according to the Performa. None of the subjects were taking vitamin D preparations or any drugs known to interfere with vitamin D metabolism. None of them had past or present history of hepatic or renal disorders.

Clinical laboratory measurements included estimation of fasting blood sugar, HBa1c, Lipid profile, and $25 \mathrm{OH}$ vitamin D levels.

Serum glucose was measured by enzymatic method with hexokinase, while immunoturbidometry was used to estimate Hba1C. Lipid profile was estimated by homogenous enzymatic calorimetric assay. Serum 25-0H-D was measured using enzyme immunoassay kits (Immunodiagnostic Systems Ltd., UK) and quality control materials provided by the manufacturer. The intra- and inter-assay coefficients of variation were $4.56 \%$ and $4.69 \%$, respectively.

\section{Criteria for Vitamin D Levels[10]}

- Serum 25 hydroxy vitamin D - 25(OH)D, levels was measured to determine the vitamin D status.

- Vitamin D deficiency; if serum 25(OH)D was = or $<75 \mathrm{nmol} /$ liter or, $=$ or $<30 \mathrm{ng} / \mathrm{ml}$.

- Vitamin D sufficiency; if serum 25(OH) D was $>75 \mathrm{nmol} / \mathrm{liter}$ or $>30 \mathrm{ng} / \mathrm{ml}$.

Statistical Methods: Descriptive statistical analysis has been carried out in the present study. Results on continuous measurements are presented on Mean \pm SD (Min-Max) and results on 
categorical measurements are presented in Number (\%). Significance is assessed at $5 \%$ level of significance.

RESULTS: Our study included 242 subjects, with 139 being cases and 103 controls. Both the groups were comparable to each other in demographic variables like age, sex. Among 139 cases, 66 were males and 73 females. Among 103 controls, 49 were males and 54 females.

\begin{tabular}{|l|c|c|c|c|}
\hline \multirow{2}{*}{ Gender } & \multicolumn{2}{|c|}{ Control } & \multicolumn{2}{c|}{ Cases } \\
\cline { 2 - 5 } & No & $\mathbf{\%}$ & No & \% \\
\hline Male & 49 & 47.6 & 66 & $\mathbf{4 7 . 5}$ \\
\hline Female & 54 & 52.4 & 73 & $\mathbf{5 2 . 5}$ \\
\hline Total & $\mathbf{1 0 3}$ & $\mathbf{1 0 0 . 0}$ & $\mathbf{1 3 9}$ & $\mathbf{1 0 0 . 0}$ \\
\hline
\end{tabular}

Table 1: Gender distribution of patients studied

Mean age of controls was $47.02 \pm 8.01$ years and that of cases was $51.20 \pm 8.79$ years. Majority of study subjects were in 41 to 60 yrs. age group.

Duration of diabetes mellitus among cases varied from newly detected to $30 \mathrm{yrs}$. There were 20 newly detected diabetics and majority of them were diabetics of 1 to 10 yrs. duration.

Co morbidities in both groups were documented with 58 of 139 cases having hypertension while 14 of 103 controls had hypertension. Out of 139 cases, 98 (70.58\%) had dyslipidemia (Table 2).

\begin{tabular}{|c|c|c|c|c|}
\hline \multirow[t]{2}{*}{ Comorbid conditions } & \multicolumn{2}{|c|}{$\begin{array}{l}\text { Control } \\
(n=103)\end{array}$} & \multicolumn{2}{|c|}{$\begin{array}{c}\text { Cases } \\
(n=139)\end{array}$} \\
\hline & No & $\%$ & No & $\%$ \\
\hline Nil & 82 & 79.6 & 75 & 54.0 \\
\hline Yes & 21 & 20.4 & 64 & 46.0 \\
\hline - Hypertension & 14 & 13.6 & 58 & 41.7 \\
\hline - Hypothyroid & 4 & 3.9 & 4 & 2.9 \\
\hline - Dyslipidemia & 1 & 1.0 & 98 & 70.58 \\
\hline - Bronchial Asthma & 2 & 1.9 & 0 & 0.0 \\
\hline
\end{tabular}

Table 2: Co-morbid conditions

46 controls and 59 cases were pure vegetarians while the remaining (i.e.57 controls and 80 cases) were taking a mixed diet ( Table no 3 ).

\begin{tabular}{|lll|}
\hline & Pure vegetarians & Mixed diet \\
\hline Cases & 59 & 80 \\
\hline controls & 46 & 57 \\
\hline
\end{tabular}

Table 3:-Diet 
22 cases and 21 controls had BMI $>30 \mathrm{~kg} / \mathrm{m} 2$. Mean waist circumference in controls was 85.51 $\pm 8.39 \mathrm{cms}$, while in cases it was $90.03 \pm 8.3$, with $\mathrm{p}$ value $<0.001$.

\begin{tabular}{|l|c|cc|}
\hline \multicolumn{1}{|c|}{ Variables } & $\begin{array}{c}\text { Controls } \\
(\mathbf{n = 1 0 3 )}\end{array}$ & $\begin{array}{c}\text { Cases } \\
(\mathbf{n = 1 3 9 )}\end{array}$ & P value \\
\hline BMI(kg/m2) & $25.87 \pm 4.39$ & $26.62 \pm 4.01$ & $\mathbf{0 . 1 7 2}$ \\
\hline Waist circumference & $85.51 \pm 8.39$ & $90.03 \pm 8.30$ & $<\mathbf{0 . 0 0 1} * *$ \\
\hline SBP (mm Hg) & $127.88 \pm 11.39$ & $135.21 \pm 17.22$ & $<\mathbf{0 . 0 0 1 * *}$ \\
\hline DBP (mm Hg) & $82.45 \pm 7.24$ & $84.65 \pm 9.62$ & $\mathbf{0 . 0 5 3 +}$ \\
\hline HbA1c & $\mathbf{6 . 2 2 \pm 0 . 6 2}$ & $\mathbf{9 . 0 2 \pm 1 . 9 7}$ & $<\mathbf{0 . 0 0 1 * *}$ \\
\hline
\end{tabular}

Table 4: Comparison of Anthropometric and blood glucose parameters.

Out of 242 subjects, 211 were found to have vitamin D deficiency with levels of 25(OH)D $\leq 30 \mathrm{ng} / \mathrm{ml}$. 122 cases and 89 controls were Vitamin D deficient while only 17 cases and 14 controls wereVit D sufficient (>30ng/ml) ( Table 5).

\begin{tabular}{|l|l|l|l|l|}
\hline Vitamin D ng/dl & \multicolumn{2}{l|}{$\begin{array}{l}\text { Control } \\
(\mathbf{n = 1 0 3 )}\end{array}$} & $\begin{array}{l}\text { Cases } \\
(\mathbf{n = 1 3 9 )})\end{array}$ \\
\cline { 2 - 5 } & No & $\%$ & No & $\%$ \\
\hline $\mathbf{3 0 . 0}$ & 89 & 86.4 & 122 & 87.8 \\
\hline$>\mathbf{3 0 . 0}$ & 14 & 13.6 & 17 & 12.2 \\
\hline Mean \pm SD & $18.48 \pm 9.84$ & $19.05 \pm 9.77$ \\
\hline \hline Inference & \multicolumn{4}{|l|}{ Levels of Vitamin D not statistically significant with $\mathrm{p}=0.658$} \\
\hline
\end{tabular}

Table 5:-vitamin D levels in cases and controls.

Mean value of Vitamin D among cases was $19.05 \pm 9.77 \mathrm{ng} / \mathrm{ml}$ and among controls $18.48 \pm 9.84 \mathrm{ng} / \mathrm{ml}$ which was not statistically significant.

Males who were taking mixed diet had slightly higher levels of vitamin Dwhich was not statistically significant. (Table 6)

\begin{tabular}{|l|l|l|l|}
\hline \multirow{2}{*}{ Demographic parameters } & \multicolumn{2}{|l|}{ Vitamin D ng/dl } & \multirow{2}{*}{ P value } \\
\cline { 2 - 4 } & $\begin{array}{l}\text { Controls } \\
(\mathrm{n}=103)\end{array}$ & $\begin{array}{l}\text { Cases } \\
(\mathrm{n}=139)\end{array}$ & \\
\hline Gender & & & \\
\hline Male & $20.39 \pm 11.13$ & $20.75 \pm 10.62$ & $\mathbf{0 . 8 6 0}$ \\
\hline Female & $16.75 \pm 8.21$ & $17.51 \pm 8.73$ & $\mathbf{0 . 6 2 2}$ \\
\hline P value & $0.061+$ & $0.050^{*}$ & - \\
\hline Diet & & & \\
\hline Veg & $15.54 \pm 9.07$ & $17.77 \pm 7.91$ & $\mathbf{0 . 2 0 3}$ \\
\hline Mixed & $20.86 \pm 9.86$ & $19.74 \pm 10.62$ & $\mathbf{0 . 5 2 4}$ \\
\hline
\end{tabular}




\begin{tabular}{|l|l|ll|}
\hline \hline P value & $0.006 * *$ & 0.258 & - \\
\hline
\end{tabular}

Table 6: correlation of vitamin D levels with some demographic parameters.

DISCUSSION: Apart from calcitropic actions, vitamin D and its metabolites appear to have important effects (through paracrine/autocrine functions and gene modulation) on insulin synthesis, secretion and actions as well as components of inflammation. All these may have an influence on the pathogenesis of type 2 DM [7,11].

Our study provides estimates of vitamin D status among an urban south Indian population residing in Bangalore city. The results show high prevalence of vitamin D insufficiency/deficiency and lack of inverse association between serum $25(\mathrm{OH}) \mathrm{D}$ levels and prevalent type $2 \mathrm{DM}$.

Out of 242 study subjects, 211 i.e. $87 \%$ were found to be having less than optimal levels of vitamin D. This high prevalence of vitamin D deficiency was also noted in some of the previous studies from India [2,3]. Various factors like darker skin pigmentation, lack of adequate sun exposure and obesity, predominantly vegetarian diet may contribute to this poor vitamin D status among south Asian Indians. We found that females and subjects who were pure vegetarians had slightly lower vitamin D levels when compared males and individuals who consumed a mixed diet which was not significant.

There was no statistically significant difference in the mean values of vitamin D levels among cases and controls in the present study $(19.05 \pm 9.77 \mathrm{ng} / \mathrm{ml}$ vs. $18.48 \pm 9.84 \mathrm{ng} / \mathrm{ml}$, $\mathrm{p}=0.658$ ). Pittas et al[9], in their systematic review and meta-analysis have also found that the inverse association between serum 25(OH) D levels and prevalent type 2 DM was not very consistent. Heath $\mathrm{H}^{\text {rdet }}$ al[12] and Ishida $\mathrm{H}$ et al[13] also noticed in their studies that $25(\mathrm{OH}) \mathrm{D}$ and 1, 25(OH) D levels were not significantly different in type $2 \mathrm{DM}$ when compared to that of controls. Scragg R et al[14] in an analysis of data from participants of the Third National Health and Nutrition Examination Survey, a cross sectional survey of nationally representative sample of US population, found lack of inverse association between vitamin D status and type 2 DM in non-Hispanic blacks, despite their poor vitamin D status. But, the inverse association was very much evident in the study population belonging to other ethnicities (non-Hispanic whites and Mexican Americans). The authors have hypothesized that; this could be due to an ethnicity specific altered vitamin D endocrine system and low sensitivity to vitamin D in blacks.

The lack of inverse association between vitamin D status and type 2 DM in the present study can be attributed to small sample size, cross sectional study design and possibly other factors related to ethnicity, widespread deficiency of vitamin D and other confounding factors like dietary habits, vitamin D receptor gene polymorphism, etc.

CONCLUSION: Vitamin D deficiency is highly prevalent in India. Probably, population based prospective studies and larger interventional studies using sufficiently higher doses of vitamin D over a longer period of time, in subjects at risk for type 2 DM may establish the inverse association between type $2 \mathrm{DM}$ and vitamin D status conclusively. Additional information may be gained by using dynamic techniques like euglycemic/hyperglycemic clamps in the study design and from genetic studies analyzing vitamin D receptor gene polymorphism in the population.

Conflict of interest: The authors declare no conflict of interest. 
ACKNOWLEDGEMENTS : We thank all the volunteers who consented to take part in the study. We also thank the office bearers of API- Karnataka chapter for providing financial assistance to this project,and the staff of department of Neurochemistry NIMHANS for their cooperation in processing serum samples for vitamin D estimation.

\section{REFERENCES:}

1. Sicree R, Shaw J, Zimmet P, Prevalence and projections in: Diabetes Atlas $3^{\text {rd }}$ edition. Brussels, Belgium: International Diabetes Federation 2006: 16-104.

2. Harinarayan CV, Ramalakshmi T, Venkata Prasad V, High prevalence of low dietary calcium and low vitamin D status in healthy south Indians. Asia Pac J ClinNutr 2000:72,690-693.

3. R.Goswami, S.K.Mishra\&N.Kochupillai, Prevalence and potential significance of vitamin D deficiency in Asian Indians. Indian J Med Res March 2008: 127, 229-238.

4. R Goswami, N Kochupillai et al, Presence of 25(OH)D Deficiency in a Rural North Indian Village Despite Abundant Sunshine. JAPI 2008: 56,755-757.

5. Anthony W Norman: From vitamin D to hormone D; fundamentals of the vitamin D endocrine system essential for good health. Am J ClinNutr 2008; 88(2):491s-499s.

6. Daniel Bikle: Nonclassic Actions of Vitamin D. J ClinEndocrinolMetab 2009; 94(1):26-34.

7. ZehraOzfirat, Tahseen A Chowdhury: Vitamin D deficiency and Type 2 diabetes. Postgrad Med J 2010; 86:18-25.

8. Chiu KC, Chu A, Go VL, Saad MF. Hypovitaminosis D is associated with insulin resistance and beta cell dysfunction. Am J ClinNutr 2004; 79: 820-825.

9. Pittas AG, Lau J, Hu FB, Dawson-Hughes B. The role of vitamin D and calcium in type 2 diabetes. A systematic review and meta-analysis. J ClinEndocrinolMetab 2007; 92: 2017-29.

10. Holick MF, Chen TC. Vitamin D deficiency: a worldwide problem with health consequences. Am J ClinNutr 2008; 87(4): 1080s-1086s.

11. Mc Carty MF,Poor vitamin D status may contribute to high risk of insulin resistance, obesity and cardiovascular disease in Asian Indians. Med Hypothesis 2009;72:647-651.

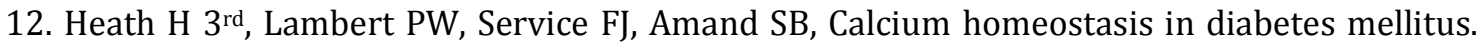
J ClinEndocrinolMetab 1979;49(3):462-466.

13. Ishida H, Seino Y, Matsukura S, Ikida M, Diabetic osteopenia and circulating levels of vitamin D metabolites in type 2 diabetes mellitus. Metabolism 1985;34(9):797-801.

14. Scragg R, Sowers M, Bell C. Serum 25-hydroxyvitamin D, diabetes and ethnicity in the Third National Health and Nutrition Survey. Diabetes care 2004;27(12):2813-2818. 